ORIGINAL ARTICLE

\title{
Estabilidade física e química de hidrolisados proteicos de okara microencapsulados por spray drying
}

\author{
Physical and chemical stability of microencapsulated okara \\ protein hydrolysate by spray drying
}

\author{
Ariana Justus $^{1}$ (i), Marta de Toledo Benassi ${ }^{1}$ (i), Elza louko Ida ${ }^{1}$ (i), \\ Louise Emy Kurozawa ${ }^{1,2 *}$ (i)
}

${ }^{1}$ Universidade Estadual de Londrina (UEL), Departamento de Ciência e Tecnologia de Alimentos, Londrina/PR Brasil.

${ }^{2}$ Universidade Estadual de Campinas (UNICAMP), Faculdade de Engenharia de Alimentos, Departamento de

Engenharia de Alimentos, Campinas/SP - Brasil

*Corresponding Author: Louise Emy Kurozawa, Universidade Estadual de Campinas (UNICAMP), Faculdade de Engenharia de Alimentos, Departamento de Engenharia de Alimentos, R. Monteiro Lobato, 80, CEP: 13083-862, Campinas/SP - Brasil, e-mail: louisek@unicamp.br

Cite as: Justus, A., Benassi, M. T., Ida, E. I., \& Kurozawa, L. E. (2020). Physical and chemical stability of microencapsulated okara protein hydrolysate by spray drying. Brazilian Journal of Food Technology, 23, e2019135. https://doi.org/10.1590/1981-6723.13519

\begin{abstract}
Resumo
A microencapsulação é um processo indicado para proteger substâncias que são susceptíveis à degradação ou redução da sua funcionalidade por causa de diferentes reações, por exemplo, oxidação, hidrólise, entre outras. O objetivo deste estudo foi avaliar o efeito da microencapsulação, usando como materiais de parede maltodextrina ou amido modificado, sobre a estabilidade de hidrolisados proteicos de okara. A pesquisa analisou a microestrutura, a capacidade antioxidante e a cor das amostras durante a estocagem dos pós por 120 dias a $35^{\circ} \mathrm{C}$. As micrografias obtidas por microscopia eletrônica de varredura indicaram que o processo de microencapsulação favoreceu a integridade física das partículas. A diferença de cor observada entre as amostras encapsuladas e não encapsuladas foi proveniente, provavelmente, da adição de materiais de paredes que contribuíram para a mudança da cor do pó obtido por spray drying. Os resultados indicaram que as microcápsulas obtidas por spray drying usando maltodextrina ou amido modificado mantiveram a cor dos pós e apresentaram boa habilidade em sequestrar o radical livre ABTS e teor de substâncias redutoras do reagente Folin-Ciocalteu durante a estocagem.
\end{abstract}

Palavras-chave: Okara; Capacidade antioxidante; Maltodextrina; Amido modificado; Microestrutura; Cor.

\begin{abstract}
Microencapsulation is a process used for protecting substances that are susceptible to degradation or reduction of their functionality due to different reactions such as oxidation, hydrolysis, among others. This study aimed to evaluate the effect of microencapsulation, using maltodextrin or modified starch as wall materials, on the stability of okara protein hydrolysates. We analyzed the microstructure, antioxidant capacity, and color of the samples during powder storage for 120 days at $35^{\circ} \mathrm{C}$. Micrographs obtained by scanning electron microscopy indicated that the
\end{abstract}


microencapsulation process favored the particles' physical integrity. The color difference observed between the encapsulated and unencapsulated samples was probably due to the addition of wall materials that contributed to color change of the powder obtained by spray drying. The results indicated that the microcapsules obtained by spray drying using maltodextrin or modified starch maintained the powder color and showed good ability to sequester the free radical ABTS and content of reducing substances from the Folin-Ciocalteau reagent during storage.

Keywords: Okara; Antioxidant capacity; Maltodextrin; Modified starch; Microstructure; Color.

\section{Introdução}

$\mathrm{Na}$ indústria de alimentos, é crescente o uso da microencapsulação para proteger, isolar ou controlar a liberação de determinada substância (Souza et al., 2018). Trata-se de é um processo de revestimento físico de um material ativo ou núcleo, cuja forma pode ser de pequenas partículas sólidas, gotículas de líquidos ou gases, em um material de parede ou agente de encapsulação, com a função de isolar total ou parcialmente o material ativo (Gharsallaoui et al., 2007).

O processo de secagem por atomização, ou spray drying, é comumente usado para produção de microcápsulas por causa de seu baixo custo, de sua versatilidade e por ser um processo contínuo (Hoyos-Leyva et al., 2018). É adequado para secagem de materiais susceptíveis à degradação térmica em razão do curto tempo de residência do produto no interior do secador. Contribui também o fato de o produto permanecer na temperatura de bulbo úmido do ar durante a secagem, seguido pelo aumento até atingir a temperatura de saída do secador. Esse tipo de processo proporciona diversos benefícios para a indústria alimentícia, tais como eficiente retenção de voláteis, facilidade de manuseio, transporte, proteção do material ativo, estabilidade final do produto e utilização em formulações (Botrel et al., 2012; Costa et al., 2013).

Diversos biopolímeros podem ser utilizados como material de parede (Sarabandi et al., 2018). Maltodextrina, goma arábica, proteínas e amidos modificados são agentes encapsulantes utilizados com frequência (Costa et al., 2015a, 2015b; Hoyos-Leyva et al., 2018; Souza et al., 2018). As maltodextrinas são produzidas via hidrólise parcial do amido por ácido ou enzimas. São os agentes encapsulantes mais comuns por possuírem baixo custo e boa proteção contra oxidação, além de não conferirem sabor; no entanto, possuem baixa capacidade emulsificante (Goula \& Adamopoulos, 2012; Rocha et al., 2009). O amido modificado Capsul ${ }^{\circledR}$, também conhecido como amido octenilsuccinato, é um derivado obtido pela esterificação do amido com o ácido octenilsuccinato anidro, resultando em um amido hidrofobicamente modificado. Por meio da modificação, a hidrofobicidade do octenilsuccinato é introduzida, então a hidrofilicidade do amido é mantida. Como resultado, esse derivado do amido tem sido usado para o aumento da capacidade e a estabilidade das emulsões ou suspensões (Costa et al., 2015b; Souza et al., 2018).

Uma das limitações da utilização das proteínas hidrolisadas em produtos alimentares é o seu gosto amargo, o qual está relacionado à formação de pequenos peptídeos compostos, principalmente, de aminoácidos hidrofóbicos (Adler-Nissen, 1986). Alguns autores como Sarabandi et al. (2018) e Subtil et al. (2014) aplicaram a tecnologia de microencapsulação para mascarar o gosto amargo.

Os hidrolisados proteicos de okara possuem vários constituintes antioxidantes, como peptídeos bioativos, proteínas, isoflavonas e compostos fenólicos (Justus et al., 2019). A microencapsulação pode ser aplicada também sobre esses compostos para protegê-los contra as condições ambientais adversas (luz, umidade, oxigênio, radiação UV). Além disso, a microencapsulação pode conferir proteção física, uma vez que os peptídeos e os açúcares de baixa massa molecular presentes no hidrolisado proteico diminuem a temperatura de transição vítrea e aumentam a higroscopicidade do pó, acarretando alterações indesejáveis nas características físicas, como aglomeração e compactação do pó. 
O okara é um subproduto insolúvel gerado no processamento de extrato de soja e tofu. Considerando que o volume de vendas de extrato de soja no mundo alcançou 13,5 bilhões de litros em 2015 (Statista, 2018) e que cerca de $130 \mathrm{~kg}$ de okara podem resultar da produção de $1.000 \mathrm{~L}$ de extrato de soja (Wang \& Murphy, 1996), estima-se aproximadamente que 1,7 milhão de toneladas de okara seja gerado todo ano. A composição química do okara é de: $6,8 \%$ de proteínas, $3,5 \%$ de gorduras, $10,9 \%$ de fibras insolúveis e $0,5 \%$ de fibras solúveis (Justus et al., 2019). Assim, esse resíduo é pouco aproveitado como alimento, subutilizado como ração animal ou descartado, tendo um desperdício significativo de substâncias nutritivas que poderiam ser aproveitadas na alimentação humana. Uma forma de aproveitamento interessante do okara seria a obtenção de hidrolisados a partir das proteínas presentes nele. Os hidrolisados proteicos têm diversas aplicações na indústria de alimentos, podendo ser usados para fins geriátricos e infantis, visto que são mais disponíveis biologicamente para absorção, ou em suplementos e bebidas para alimentação esportiva (Sgarbieri, 1996). Também possuem efeitos benéficos para a saúde humana por ter funções antioxidantes, anti-hipertensivas e antimicrobianas (Chalamaiah et al., 2018; Jin et al., 2016).

Avaliar a estabilidade das microcápsulas é uma questão relevante quando se objetiva garantir a qualidade do produto. Sendo assim, o estudo da estabilidade dos hidrolisados proteicos de okara microencapsulados usando como material de parede maltodextrina (MD) ou amido modificado (AM), bem como hidrolisados não encapsulados (controle), foi conduzido com o objetivo de avaliar as alterações na microestrutura, cor e capacidade antioxidante nas amostras estocadas a $35^{\circ} \mathrm{C}$ por 120 dias.

\section{Material e métodos}

\subsection{Material}

O okara foi doado por uma indústria produtora de extrato de soja e estocado a $-22^{\circ} \mathrm{C}$. A protease alcalase $2.4 \mathrm{~L}^{\circledR}$ foi utilizada no processo de hidrólise enzimática para obter o hidrolisado proteico de okara. Os materiais de parede utilizados foram maltodextrina 10DE e amido modificado Capsul ${ }^{\circledR}$ (Ingredion, Mogi Guaçu, SP, Brasil).

Os reagentes 2,2'-azinobis (3-etilbenzotiazolina-6-ácido sulfônico) (ABTS), ácido 6-hidroxi-2,5,7,8tetrametilcromano-2-carboxílico (Trolox), 2,4,6-tripiridil-s-triazina (TPTZ), reagente de Folin-Ciocalteu e ácido gálico foram adquiridos da Sigma-Aldrich Brasil (São Paulo, SP, Brasil). Todos os reagentes utilizados foram de grau analítico ou grau para HPLC.

\subsection{Obtenção do hidrolisado proteico de okara}

A hidrólise proteica do okara com alcalase foi conduzida de acordo com o método $\mathrm{pH}$-stat (Adler-Nissen, 1986). O okara foi homogeneizado em água destilada (1:4, p/p) sob agitação. A dispersão obtida foi aquecida a $50{ }^{\circ} \mathrm{C}$, e o seu $\mathrm{pH}$, ajustado para 9,0 com solução de $\mathrm{NaOH} 1 \mathrm{M}$. A enzima foi adicionada a uma concentração de $5 \mathrm{~g} / 100 \mathrm{~g}$ de proteína. A hidrólise enzimática passou por monitoramento de titulação contínua de solução de $\mathrm{NaOH} 1 \mathrm{M}$ para manter o pH constante. Quando nenhuma alteração adicional no pH foi observada, a enzima foi inativada por aquecimento a $85^{\circ} \mathrm{C}$ por $15 \mathrm{~min}$, seguido de resfriamento em banho de gelo. A mistura foi centrifugada a $5.228 \times \mathrm{g}\left(5804 \mathrm{R}\right.$, Eppendorf, Hamburgo, Alemanha) a $4{ }^{\circ} \mathrm{C}$ por $20 \mathrm{~min}$ para separar o precipitado do hidrolisado proteico. O volume consumido de $\mathrm{NaOH}$ no final da reação enzimática foi utilizado com o objetivo de calcular o grau de hidrólise $(34,8 \% \pm 0,27 \%)$ do hidrolisado proteico, conforme descrito por Adler-Nissen (1986). O hidrolisado apresentou conteúdo de proteína de $1,4 \% \pm 0,01 \%$ de proteína (base úmida), obtido de acordo com o método da AOAC (Association of Official Analytical Chemists, 2012). 


\subsection{Microencapsulação do hidrolisado proteico de okara por spray drying}

Os materiais da parede (maltodextrina ou amido modificado) foram dissolvidos no hidrolisado proteico a uma concentração de $10 \%(\mathrm{p} / \mathrm{p})$ (Kurozawa et al., 2011). A secagem e a microencapsulação foram conduzidas em um spray dryer de bancada (modelo SD-05, LabPlant, Chelmsford, Inglaterra). O bico atomizador foi do tipo duplo fluido com um orifício de $0,7 \mathrm{~mm}$ de diâmetro. As condições do processo foram: temperatura do ar de entrada e saída de $180 \pm 5{ }^{\circ} \mathrm{C}$ e $100 \pm 8^{\circ} \mathrm{C}$, respectivamente; vazão de alimentação e do ar de secagem de $420 \mathrm{~mL} / \mathrm{h}$ e $73 \mathrm{~m}^{3} / \mathrm{h}$, respectivamente; e pressão do ar comprimido de 1,4 bar. As microcápsulas obtidas foram armazenadas a $-22{ }^{\circ} \mathrm{C}$ até o início da avaliação da estabilidade. A vazão do ar de secagem e a pressão do ar comprimido foram definidas de acordo com as recomendações do fabricante do equipamento. A temperatura do ar de saída foi medida durante os experimentos. As outras condições do processo foram definidas em testes preliminares.

Para verificar o efeito da microencapsulação, o estudo da estabilidade também foi realizado para o hidrolisado proteico não encapsulado em pó (amostra controle). Como não se conseguiu obtê-lo por spray drying, o hidrolisado proteico do okara foi liofilizado por aproximadamente $36 \mathrm{~h}$ a $-40{ }^{\circ} \mathrm{C}$ (Labconco, Lyph.Lock 1L). Não foi possível secá-lo em spray drying por causa da sua baixa temperatura de transição vítrea, cujo valor da amostra anidra foi de $55,1{ }^{\circ} \mathrm{C}$ (dado obtido em estudos prévios e não publicados), valor bem inferior à temperatura do ar de saída do secador $\left(100 \pm 8^{\circ} \mathrm{C}\right)$.

\subsection{Estudo da estabilidade}

A estabilidade dos produtos microencapsulados e não encapsulados (controle) passou por avaliação a cada 15 dias, totalizando 120 dias de estocagem. A temperatura de estocagem foi de $35^{\circ} \mathrm{C}$, valor recomendado por Labuza \& Schmidl (1985) para estudos de estabilidade acelerada. Os pós foram embalados em duas embalagens e armazenados em BOD (TE-402, Tecnal, Piracicaba, SP, Brasil). Na embalagem primária, foram utilizados recipientes plásticos com tampa de polietileno de alta densidade (PEAD), enquanto na embalagem secundária, potes plásticos de polipropileno (PP) com vedação na tampa, com o intuito de oferecer maior barreira de proteção de umidade e luz (protegidos com papel alumínio).

\subsection{Parâmetros físicos e químicos}

Os parâmetros de cor das amostras microencapsuladas e não encapsuladas (controle) foram determinados utilizando um colorímetro (Minolta CR-400, Osaka, Japão) com escala CIELab ( $L^{*}, a^{*}$ e $\left.b^{*}\right)$. As medições foram feitas em triplicata, usando o iluminante D-65, e expressas em termos de luminosidade $L^{*}\left(L^{*}=0\right.$ para preto e $L^{*}=100$ para branco) e parâmetros $a^{*}\left(+a^{*}\right.$ para vermelho e $-a^{*}$ para verde) e $b^{*}\left(+b^{*}\right.$ para amarelo $\mathrm{e}-b^{*}$ para azul). A tonalidade cromática ${ }^{\circ} h$ e croma $C^{*}$ foram calculados pelas Equações $1 \mathrm{e} 2$, segundo o sistema CIELAB 1976 (Hutchings et al., 2013).

$$
\begin{aligned}
& { }^{\circ}=\operatorname{arctg}\left(\frac{b^{*}}{a^{*}}\right) \\
& C^{*}=\sqrt{a^{* 2}+b^{* 2}}
\end{aligned}
$$

As microestruturas das micropartículas foram avaliadas por microscopia eletrônica de varredura (FEI Quanta 200, FEI Company, Holanda), observadas no tempo inicial (0 dia) e final (120 dias) de cada tratamento. As amostras foram fixadas em suportes metálicos (stubs) com fita de carbono dupla face e, em seguida, metalizadas com uma liga de ouro com grau de pureza de 99,6\% em um metalizador (Sputter Coster SCD 050 BAL-TEC), a uma taxa de recobrimento de $0,51 \mathrm{~A} / \mathrm{s}$, por $98 \mathrm{~s}$, a $40 \mathrm{~mA}$ de voltagem e $5 \times 10^{-1} \mathrm{mba}$. As microestruturas das micropartículas foram avaliadas com ampliação variando de 300 a $6.000 \times$. 
A capacidade antioxidante dos hidrolisados proteicos de okara microencapsulados e não encapsulados foi avaliada por dois métodos: capacidade redutora pelo teor de substâncias redutoras do reagente Folin-Ciocalteu (FC) e capacidade de sequestrar o radical livre ABTS. Todos os ensaios foram realizados em triplicata.

Previamente à análise da capacidade antioxidante, as amostras foram dissolvidas em $10 \mathrm{~mL}$ de água destilada, resultando em uma solução com $2 \%$ de proteína, e agitadas (Ika Works, Ika Works, Inc, Wilmington, EUA) a $25^{\circ} \mathrm{C}$ por $10 \mathrm{~min}$. Em seguida, as soluções foram centrifugadas a $794 \times$ g e a $4{ }^{\circ} \mathrm{C}$ por 15 min (Centrifuge 5804R, Eppendorf, Hamburgo, Alemanha), obtendo-se um extrato aquoso.

A capacidade redutora (FC) foi determinada pelo método colorimétrico de Folin-Ciocalteu (Kumazawa et al., 2002), que é usualmente empregado para estimar o teor compostos fenólicos totais. O total de $0,5 \mathrm{~mL}$ da amostra contendo os compostos fenólicos foi misturado com $0,5 \mathrm{~mL}$ de reativo de Folin-Ciocalteu $0,9 \mathrm{~N}$ e, em seguida, agitado, com adição de $0,5 \mathrm{~mL}$ de solução de carbonato de sódio $10 \%$; então, foi mensurada a absorbância a $760 \mathrm{~nm}$ após $1 \mathrm{~h}$. Uma curva analítica com padrão de ácido gálico $(0,004-0,016 \mathrm{mg} / \mathrm{mL})$ foi utilizada para expressar os resultados obtidos de absorbância em concentração de ácido gálico.

Para o método ABTS, foi utilizado o protocolo de Sánchez-González et al. (2005), com modificações. $\mathrm{O}$ cátion $\mathrm{ABTS}^{+}$foi produzido pela reação de solução aquosa $7 \mathrm{mM} \mathrm{ABTS}$ com persulfato de potássio $140 \mathrm{mM}$ e armazenado em vidro âmbar em temperatura ambiente por $16 \mathrm{~h}$. A solução $\mathrm{ABTS}^{+}$foi diluída com solução salina tamponada com fosfato $20 \mathrm{mM}(\mathrm{pH} 7,4)$ até uma absorbância de 0,700 a $730 \mathrm{~nm}$. Para a reação, $10 \mu \mathrm{L}$ das amostras foram diluídas em $4 \mathrm{~mL}$ de solução $\mathrm{ABTS}^{+}$, e, após 6 min do início da reação, foram realizadas as leituras em espectrofotômetro a $730 \mathrm{~nm}$. Uma curva analítica com padrão de Trolox $(1,25-10 \mu \mathrm{M})$ foi empregada para expressar os resultados obtidos de absorbância em Trolox.

Os resultados de ABTS e FC foram expressos em $\mu$ mol de equivalente de Trolox (TE)/g de sólidos de hidrolisado proteico e em mg de equivalentes de ácido gálico (GAE)/g de sólidos de hidrolisado proteico, respectivamente, na qual foram desconsiderados os sólidos do material de parede.

\subsection{Análise estatística}

Para avaliação conjunta dos dados, foi realizada uma análise de componentes principais (ACP), considerando os parâmetros de cor $\left(\mathrm{L}^{*}, \mathrm{C}^{*} \mathrm{e}^{\circ} \mathrm{h}\right)$ e capacidade antioxidante como variáveis ativas, e o tempo como variável suplementar. Os resultados foram também avaliados por meio da análise hierárquica de agrupamento (AHA) com as variáveis ativas da ACP. A distância euclidiana foi considerada como medida de dissimilaridade, e o agrupamento não ponderado aos pares, para formar os grupos. Para ambas as análises, foi empregado o software Statistica 7.0 (Statsoft, Tulsa, EUA).

\section{Resultados e discussão}

\subsection{Estabilidade dos hidrolisados proteico de okara durante estocagem}

\subsubsection{Microestrutura dos pós}

As microestruturas externas das micropartículas dos hidrolisados proteicos de okara encapsulados e não encapsulados são apresentadas na Figura 1. Elas foram avaliadas no tempo inicial e final de 120 dias de estocagem a $35^{\circ} \mathrm{C}$. 

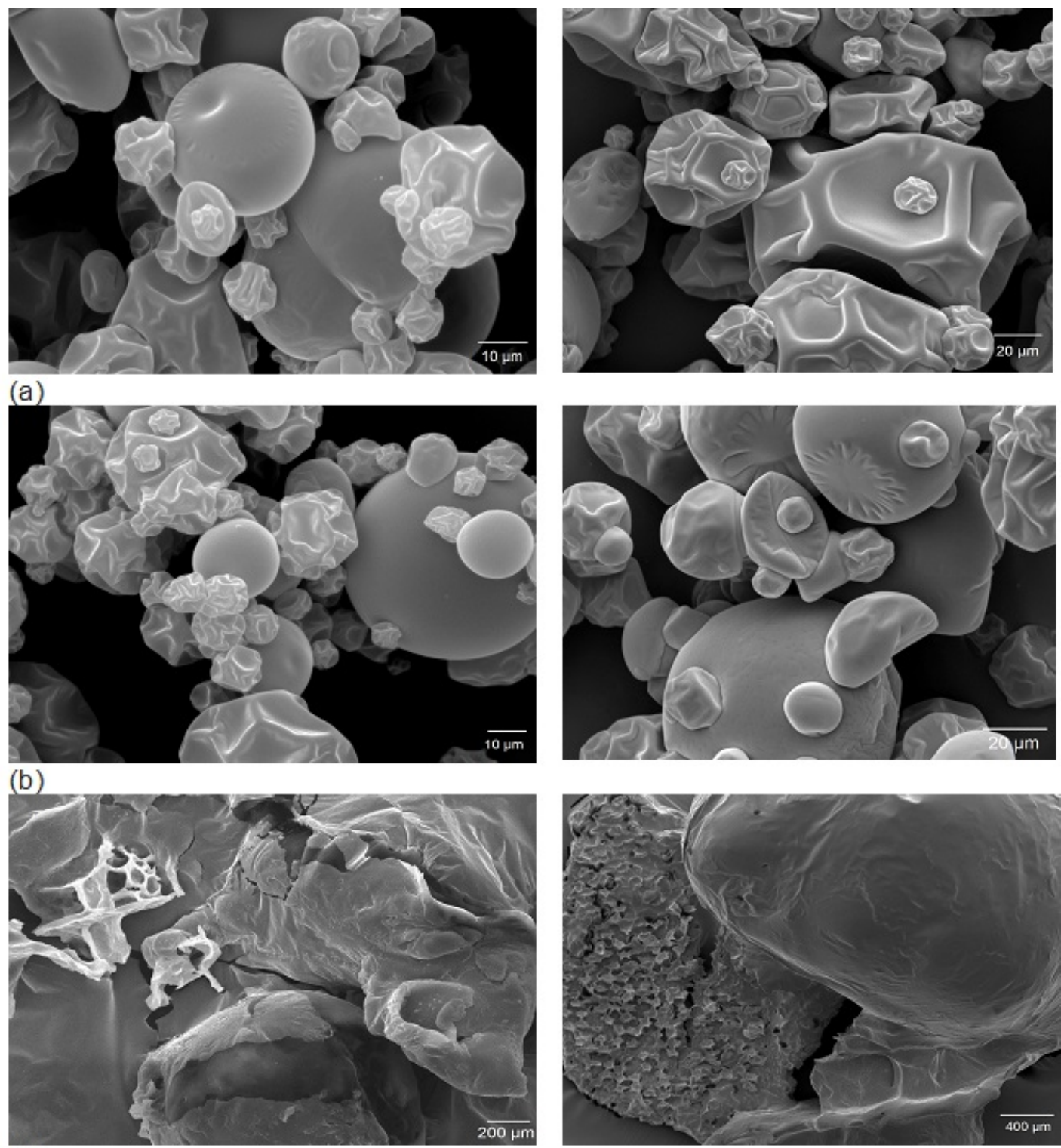

(c)

Figura 1. Micrografias eletrônicas de varredura dos hidrolisados proteicos microencapsulados com amido modificado (a) e maltodextrina (b), bem como a amostra controle (c). As figuras à esquerda são referentes ao tempo inicial e as

figuras à direita, após 120 dias de estocagem a $35^{\circ} \mathrm{C}$. As figuras à esquerda possuem um aumento de $6.000 \times \mathrm{e}$ $400 \times$ para as amostras microencapsuladas e controle, respectivamente. As figuras à direita possuem um aumento de $3.000 \times$ e $300 \times$ para as amostras microencapsuladas e controle, respectivamente.

A integridade das estruturas dos pós microencapsulados obtidos por spray drying para ambos os materiais de parede, maltodextrina e amido modificado, foi mantida durante a estocagem dos pós. As partículas apresentaram paredes contínuas sem rachaduras ou colapsos, o que é importante para garantir menor permeabilidade a gases e maior proteção e retenção do material ativo. Para as amostras encapsuladas e avaliadas no tempo inicial (Figuras 1a e 1b, à esquerda), as microscopias revelaram a presença de partículas esféricas e lisas, além de estruturas com formatos irregulares. Partículas obtidas por spray drying são geralmente esferas ocas, e a formação de vacúolos pode ser causada pelo processo de encolhimento que ocorre após o endurecimento da superfície externa, seguido pela expansão das bolhas de ar que estão presas dentro da gotícula, pulverizadas na câmara de secagem. Os mecanismos associados à formação de vazios estão relacionados com a expansão das partículas durante os últimos estágios do processo de secagem (Sarabandi et al., 2018). 
Avaliando o efeito da estocagem na morfologia das micropartículas formuladas com amido modificado (Figura 1a), há uma maior quantidade de partículas murchas após 120 dias de estocagem. Apesar do reconhecido aumento da estabilidade alcançada pelos alimentos quando armazenados a uma temperatura abaixo da de transição vítrea, certos materiais amorfos, tais como carboidratos, exibem mobilidade molecular suficiente que permite alterações físico-químicas tempo-dependentes. Tal fenômeno é denominado envelhecimento físico (physical aging) (Telis \& Tonon, 2017). Provavelmente o encolhimento das partículas com amido modificado após 120 dias de estocagem pode ter sido em razão das alterações nas propriedades mecânicas do produto causadas pelo envelhecimento físico (Sandoval \& Müller, 2017).

Já o hidrolisado proteico controle, obtido pelo processo de liofilização, apresentou partículas irregulares e porosas, características de produtos liofilizados. Após 120 dias, houve a perda da integridade do produto, provavelmente por causa da absorção de umidade do ambiente. Pelas micrografias, o hidrolisado proteico liofilizado apresentou características bem diferentes dos pós obtidos por spray drying. Poucas partículas ficaram aderidas aos suportes metálicos (stubs) e puderam ser observadas; as demais se fundiram por causa do ganho de umidade (Figura 1). Nas micrografias apresentadas, não foi possível observar com nitidez o fenômeno de absorção de umidade; entretanto, tal comportamento foi verificado visualmente no momento da análise. Esse fenômeno também foi reportado por Kurozawa et al. (2009) para hidrolisados proteicos de frango. A alta higroscopicidade do hidrolisado proteico controle pode ser em razão da presença de peptídeos e açúcares de baixa massa molecular, que apresentam baixos valores de transição vítrea. Assim, o hidrolisado proteico liofilizado teve menor estabilidade física por causa da maior capacidade de absorção de água durante o preparo das lâminas, mesmo em condições de baixa atividade de água. A adição de materiais de parede com peso molecular e $\mathrm{T}_{\mathrm{g}}$ mais elevados do que os peptídeos e os açúcares presentes na amostra controle confere ao hidrolisado proteico melhor estabilidade dos pós durante o período de armazenamento.

\subsubsection{Avaliação da cor e capacidade antioxidante}

Nas Figuras 2 e 3, são apresentados os resultados das cinéticas dos parâmetros de cor $\left(L^{*}, C^{*}\right.$ e $\left.{ }^{\circ} h\right)$, capacidade antioxidante (método ABTS) e capacidade redutora (FC), respectivamente, durante estocagem dos pós a $35^{\circ} \mathrm{C}$ por 120 dias. 

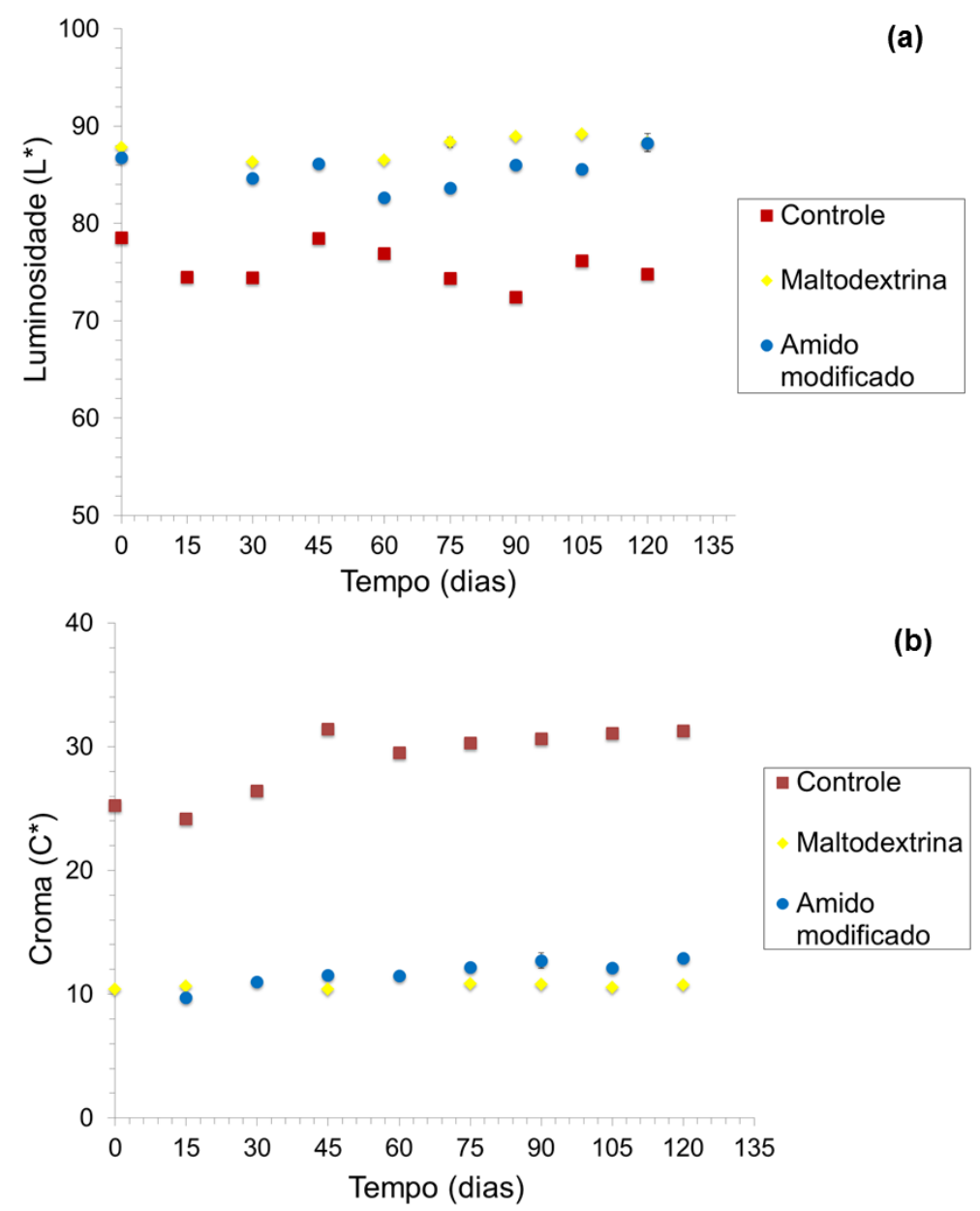

(b)

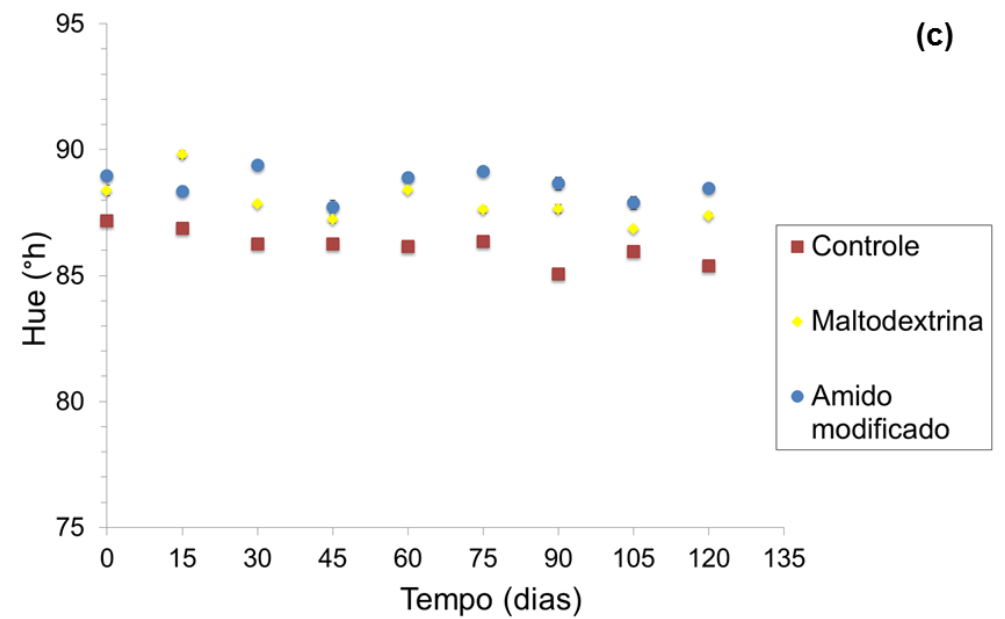

Figura 2. Cinética dos parâmetros de cor dos hidrolisados proteicos de okara microencapsulados com maltodextrina e amido modificado Capsul ${ }^{\circledR}$ durante a estocagem a $35^{\circ} \mathrm{C}$. Controle é referente à amostra liofilizada não microencapsulada: (a) luminosidade $\mathrm{L}^{*}$, (b) croma $\left(\mathrm{C}^{*}\right) \mathrm{e}(\mathrm{c})$ tonalidade cromática $\left({ }^{\circ} \mathrm{h}\right)$ 

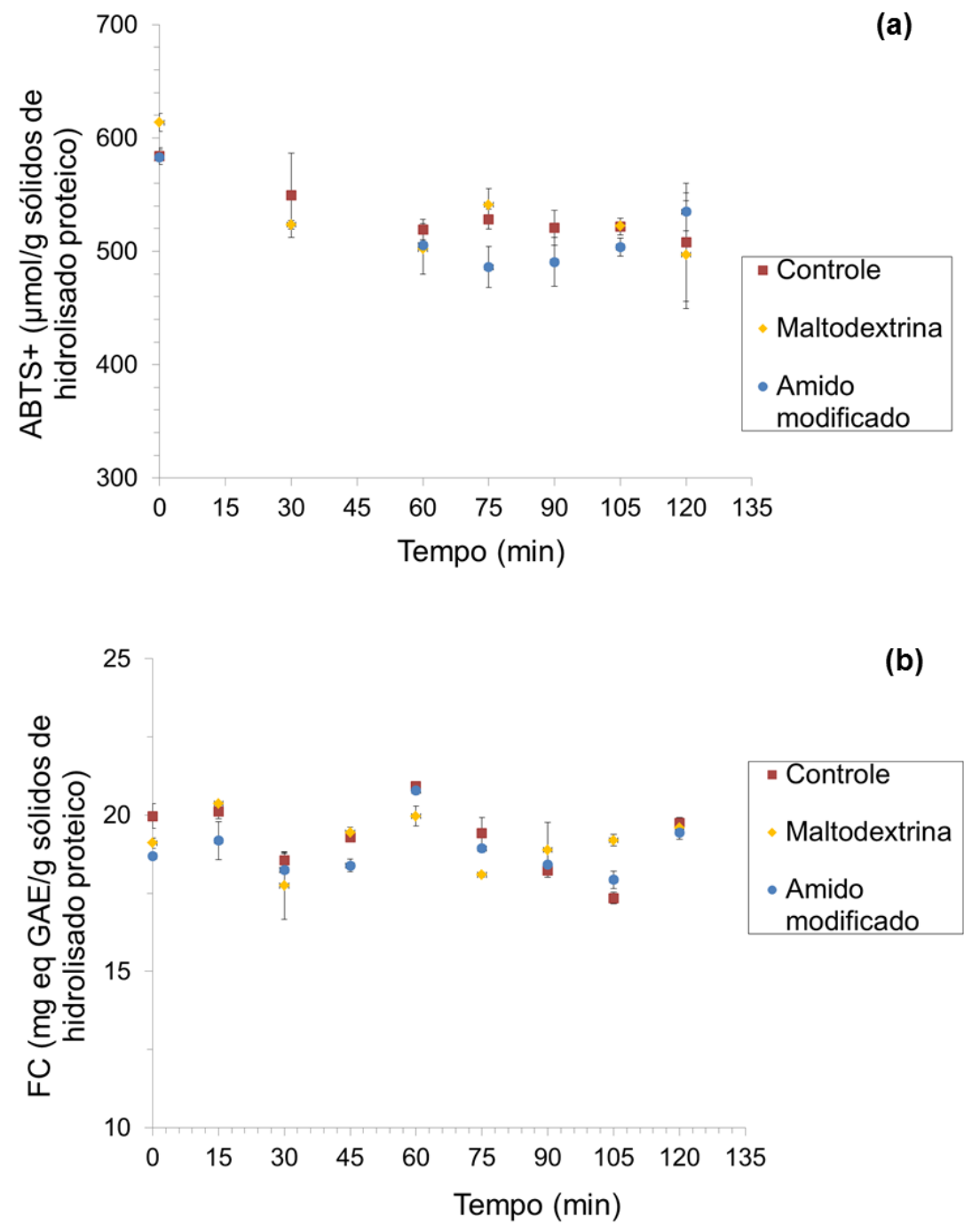

Figura 3. Cinética da capacidade antioxidante de hidrolisados proteicos de okara microencapsulados com maltodextrina e amido modificado Capsul ${ }^{\circledR}$ durante estocagem a $35^{\circ} \mathrm{C}$. Controle é referente à amostra liofilizada não microencapsulada: (a) método ABTS e (b) capacidade redutora (FC). GAE é o equivalente de ácido gálico.

Os hidrolisados proteicos encapsulados apresentaram luminosidade maior $\left(L^{*}\right.$ de 87$)$ do que o controle ( $L^{*}$ de 76), em média, por causa, provavelmente, do efeito da cor mais clara dos agentes encapsulantes. No decorrer do tempo de estocagem, para todas as amostras, não houve uma tendência dos resultados de luminosidade, na qual estes oscilaram durante a estocagem (Figura 2a).

Analisando a Figura 2b, observa-se que a amostra controle apresentou uma cor mais saturada $\left(C^{*}\right.$ de 29$)$ que as amostras microencapsuladas $\left(C^{*}\right.$ de 11). O croma define o grau de pureza da cor (Silva et al., 2017). A diferença de saturação de cor das amostras microencapsuladas pode ser relacionada à adição de maltodextrina e amido modificado, que contribuíram para a mudança da cor do pó obtido por spray drying. Não foi verificada uma tendência na variação da saturação da cor dos pós microencapsulados com maltodextrina e amido modificado ao longo do tempo de estocagem. Entretanto houve aumento de até $25 \%$ do $C^{*}$ da amostra controle estocado por 120 dias (Figura 2b).

Com relação à tonalidade cromática $\left({ }^{\circ} h\right)$, os resultados oscilaram ao longo da estocagem para todas as amostras (Figura 2c), não sendo possível verificar uma tendência dos valores com o tempo. Em todos os tratamentos, os valores estão compreendidos entre 85 e $90^{\circ}$, tendendo à tonalidade de amarelo, sendo que a 
amostra controle apresentou uma tendência de tonalidade amarelo-alaranjada, e os pós microencapsulados, tonalidade amarelada.

Na Figura 3a, é apresentado o comportamento das amostras encapsuladas e controle em relação à capacidade de sequestro dos radicais catiônicos ABTS. No período estudado, foi possível notar que os materiais apresentaram boa manutenção da capacidade antioxidante, mesmo sem a proteção do material de parede, acima de $80 \%$ nos três casos. Sarabandi et al. (2018) obtiveram hidrolisados de caseína utilizando alcalase e pancreatina e microencapsularam com maltodextrina. Os autores observaram que, mesmo após o processo de microencapsulação, os pós de caseína hidrolisados mantiveram a capacidade antioxidante pelo método ABTS em 77,5\% e 91,6\%, respectivamente.

Os resultados da capacidade redutora oscilaram durante a estocagem (Figura 3b). Provavelmente se o tempo de estocagem fosse superior a 120 dias, um comportamento da capacidade redutora ao longo do tempo poderia ser observado. Constatou-se um resultado inesperado em relação à amostra controle, que conseguiu manter a capacidade redutora e de sequestro de radicais livres durante o tempo do experimento (Figura 3). Apesar de a amostra controle ter sido submetida a um processo de secagem realizada em baixa temperatura (liofilização) do que o empregado para os microencapsulados (spray drying), esperava-se menor estabilidade do controle durante estocagem com redução da capacidade redutora, uma vez que o material não estava protegido e ocorreu uma maior alteração na estrutura desse produto (Figura 1).

Para avaliar de forma global as características dos pós, empregou-se análise multivariada. Em uma solução bidimensional, os componentes principais I e II explicaram 75\% da variabilidade dos dados (Figura 4a). A AHA e a ACP indicam separação em dois grupos: um grupo foi composto de amostras do tratamento controle (hidrolisado proteico não encapsulado), alocado na região esquerda no gráfico; e outro, pelos hidrolisados microencapsulados com maltodextrina e amido modificado, alocado à direita (Figuras 4a, 4c). Conforme discutido anteriormente na parte dos resultados de cinética (Figuras 2, 3), nas condições estudadas, não se observou discriminação pelo tempo de estocagem, e as amostras microencapsuladas com os dois diferentes materiais de parede foram caracterizadas como semelhantes com relação à cor e à capacidade antioxidante. 


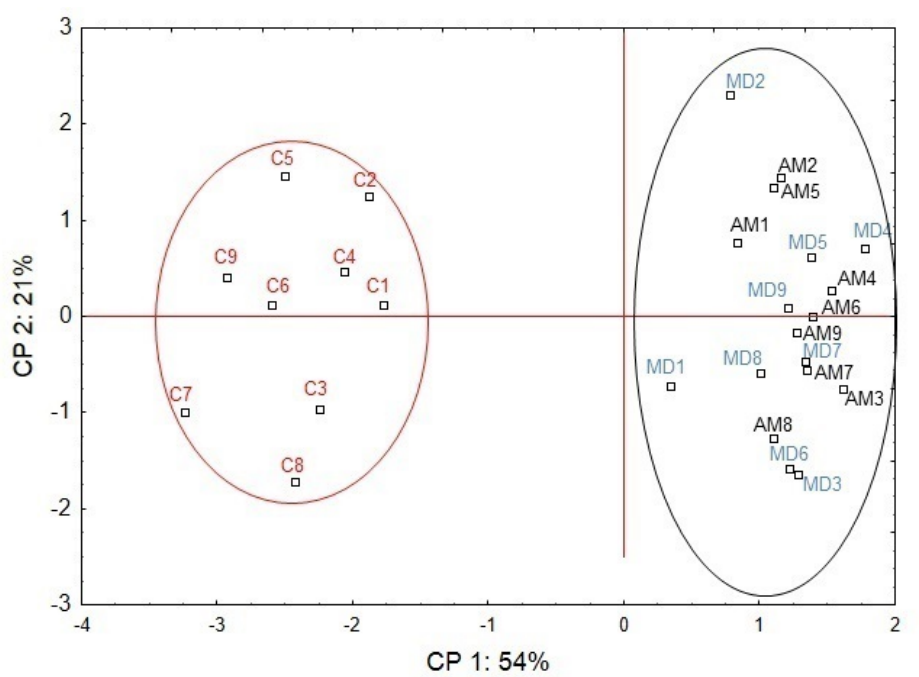

(a)

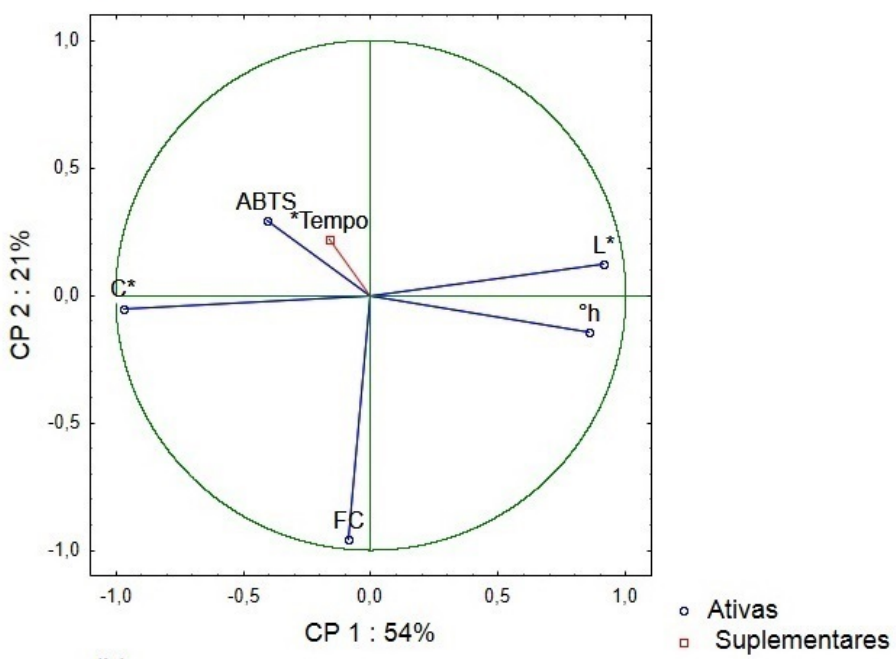

(b)

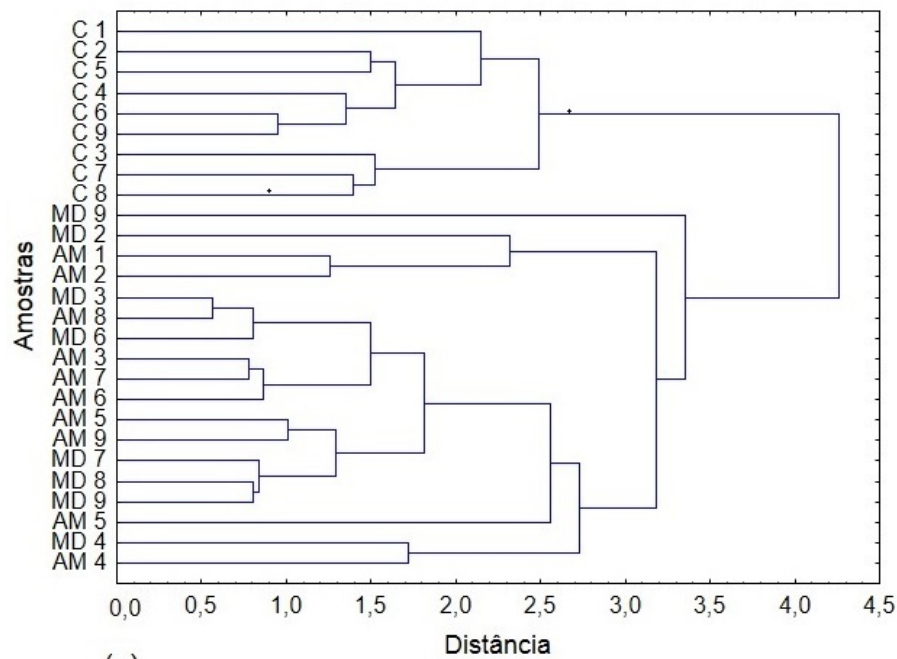

(c)

Figura 4. Hidrolisados proteicos de okara caracterizados pela cor e pela capacidade antioxidante: projeção das amostras

(a) e variáveis (b) pela análise de componentes principais e dendrograma para definição dos agrupamentos (c). 
Amostras: letras maiúsculas identificam o tratamento $(\mathrm{C}$ : controle; $\mathrm{AM}$ : amido modificado; MD: maltodextrina), e números, o tempo de estocagem (1, 0 dia; 2, 15 dias; 3, 30 dias; 4, 45 dias; 5, 60 dias; 6, 75 dias; 7, 90 dias; 8, 105 dias; 9, 120 dias).

A CP1, responsável por 54\% da variabilidade e pela separação dos grupos, foi negativamente associada ao croma e positivamente associada à luminosidade e à tonalidade cromática. Assim, pode-se considerar que as amostras encapsuladas foram caracterizadas pela maior luminosidade e tonalidade cromática mais amarela, enquanto as amostras não encapsuladas (controle) apresentaram maior saturação (Figura 4b).

A CP2 foi associada negativamente à FC e positivamente ao método ABTS e à variável suplementar tempo de estocagem (Figura 4b). Não se observou discriminação entre o controle e as amostras microencapsuladas com diferentes materiais de parede com relação a esse componente, indicando capacidade antioxidante similar. Na literatura, não se constataram informações para microencapsulados produzidos com derivados de okara, mas Sarabandi et al. (2018) reportaram que a microencapsulação por spray drying de hidrolisados de caseína produzidos com variadas condições de processo levou à produção de partículas com distintas características físico-químicas, mas pouca diversidade na atividade antioxidante avaliada por diferentes metodologias. Resultado similar foi descrito por Akbarbaglu et al. (2019) para hidrolisados de semente de linhaça microencapsulados por spray drying em diferentes condições.

Dessa forma, pode-se sugerir que o processo de microencapsulação, independentemente do material de parede, afetou a cor do hidrolisado, mas não a sua capacidade antioxidante, que se manteve estável durante o período estudado. Verifica-se, assim, que foi possível microencapsular o hidrolisado empregando spray drying sem perda de capacidade antioxidante.

\section{Conclusão}

A microencapsulação foi eficiente para manter a integridade física dos pós desde o início até os 120 dias de estocagem. As microcápsulas obtidas por spray drying usando maltodextrina 10DE ou amido modificado mantiveram a cor dos pós e apresentaram boa capacidade antioxidante pelo método ABTS e capacidade redutora (FC). A estocagem a $35^{\circ} \mathrm{C}$ por 120 dias causou perda da integridade da estrutura do produto não encapsulado (controle), provavelmente por causa da absorção de umidade do ambiente. Essa alteração não foi suficiente, no entanto, para causar alterações na capacidade antioxidante do material controle; assim, nas condições do estudo, não foi possível verificar um efeito da proteção pela microencapsulação, sendo necessários estudos adicionais em diferentes condições para avaliar o potencial de proteção. Não houve diferença em relação ao tipo de material de parede usado para a microencapsulação do hidrolisado proteico de okara.

\section{Agradecimentos}

Este estudo foi financiado em parte pela Coordenação de Aperfeiçoamento de Pessoal de Nível Superior (CAPES), Código Financeiro 001, pelo Conselho Nacional de Desenvolvimento Científico e Tecnológico (CNPq) (473117/2013-4) e pela Fundação Araucária (160/2014). LEK, MTB e EII são bolsistas produtividade do $\mathrm{CNPq}$.

\section{Referências}

Adler-Nissen, J. (1986). Enzymic hydrolysis of food protein. London: Elsevier Applied Science Publishers.

Akbarbaglu, Z., Jafari, S. M., Sarabandi, K., Mohammadi, M., Heshmati, M. K., \& Pezeshki, A. (2019). Influence of spray drying encapsulation on the retention of antioxidant properties and microstructure of flaxseed protein hydrolysates. Colloids and Surfaces. B, Biointerfaces, 178, 421-429. PMid:30908998. http://dx.doi.org/10.1016/j.colsurfb.2019.03.038

Association of Official Analytical Chemists - AOAC. (2012). Official methods of analysis of the Association of Official Analytical Chemists. Washington: AOAC. 
Botrel, D. A., Borges, S. V., Barros, F. V., Dantas, A. V., Costa, M. G. J., \& Marques, G. R. (2012). Evaluation of spray drying conditions on properties of microencapsulated oregano essential oil. International Journal of Food Science \& Technology, 47(11), 2289-2296. http://dx.doi.org/10.1111/j.1365-2621.2012.03100.x

Chalamaiah, M., Yu, W., \& Wu, J. (2018). Immunomodulatory and anticancer protein hydrolysates (peptides) from food proteins: A review. Food Chemistry, 245, 205-222. PMid:29287362. http://dx.doi.org/10.1016/j.foodchem.2017.10.087

Costa, J. M. G., Silva, E. K., Toledo Hijo, A. C., Azevedo, V. M., \& Borges, S. V. (2015a). Physical and thermal stability of spraydried swiss cheese bioaroma powder. Drying Technology, 33(3), 346-354. http://dx.doi.org/10.1080/07373937.2014.952376

Costa, J. M. G., Silva, E. K., Toledo Hijo, A. C., Azevedo, V. M., Malta, M. R., Alves, J. G. L. F., \& Borges, S. V. (2015b). Microencapsulation of Swiss cheese bioaroma by spray-drying: process optimization and characterization of particles. Powder Technology, 274, 296-304. http://dx.doi.org/10.1016/j.powtec.2015.01.037

Costa, J. M., Borges, S. V., Hijo, A. A., Silva, E. K., Marques, G. R., Cirillo, M. Â., \& Azevedo, V. M. (2013). Matrix structure selection in the microparticles of essential oil oregano produced by spray dryer. Journal of Microencapsulation, 30(8), 717-727. PMid:23534491. http://dx.doi.org/10.3109/02652048.2013.778909

Gharsallaoui, A., Roudaut, G., Chambin, O., Voilley, A., \& Saurel, R. (2007). Applications of spray-drying in microencapsulation of food ingredients: an overview. Food Research International, 40(9), 1107-1121.

http://dx.doi.org/10.1016/j.foodres.2007.07.004

Goula, A. M., \& Adamopoulos, K. G. A. (2012). A new technique for spray-dried encapsulation of lycopene. Drying Technology, 30(6), 641-652. http://dx.doi.org/10.1080/07373937.2012.655871

Hoyos-Leyva, J. D., Bello-Pérez, L. A., Alvarez-Ramirez, J., \& Garcia, H. S. (2018). Microencapsulation using starch as wall material: A review. Food Reviews International, 34(2), 148-161. http://dx.doi.org/10.1080/87559129.2016.1261298

Hutchings, J. B., Luo, M. R., \& Ji, W. (2013). Food appearance quality assessment and specification. In D. Kilcast (Ed.), Instrumental assessment of food sensory quality (pp. 29-52). Cambridge: Wood Publishing. http://dx.doi.org/10.1533/9780857098856.1.29.

Jin, D. X., Liu, X. L., Zheng, X. Q., Wang, X. J., \& He, J. F. (2016). Preparation of antioxidative corn protein hydrolysates, purification and evaluation of three novel corn antioxidant peptides. Food Chemistry, 204, 427-436. PMid:26988521. http://dx.doi.org/10.1016/j.foodchem.2016.02.119

Justus, A., Pereira, D. G., Ida, E. I., \& Kurozawa, L. E. (2019). Combined uses of na endo- and exopeptidase in okara improve the hydrolysates via formation of aglycone isoflavones and antioxidant capacity. Lebensmittel-Wissenschaft + Technologie, 115, 108467. http://dx.doi.org/10.1016/j.Iwt.2019.108467

Kumazawa, S., Taniguchi, M., Suzuki, Y., Shimura, M., Kwon, M. S., \& Nakayama, T. (2002). Antioxidant activity of polyphenols in carob pods. Journal of Agricultural and Food Chemistry, 50(2), 373-377. PMid:11782210. http://dx.doi.org/10.1021/jf010938r

Kurozawa, L. E., Park, K. J., \& Hubinger, M. D. (2009). Effect of carrier agents on the physicochemical properties of a spray dried chicken meat protein hydrolysate. Journal of Food Engineering, 94(3-4), 326-333.

http://dx.doi.org/10.1016/j.jfoodeng.2009.03.025

Kurozawa, L. E., Park, K. J., \& Hubinger, M. D. (2011). Spray drying of chicken meat protein hydrolysate: influence of process conditions on powder property and dryer performance. Drying Technology, 29(2), 163-173.

http://dx.doi.org/10.1080/07373937.2010.482711

Labuza, T. P., \& Schmidl, M. K. (1985). Accelerated shelf-life testing of foods. Food Technology, 39(9), 57-62.

Rocha, G. A., Trindade, M. A., Netto, F. M., \& Favaro-Trindade, C. S. (2009). Microcapsules of a casein hydrolysate: Production, characterization, and application in protein bars. Food Science \& Technology International, 15(4), 407-413. http://dx.doi.org/10.1177/1082013209346042

Sánchez-González, I., Jiménez-Escrig, A., \& Saura-Calixto, F. (2005). In vitro antioxidant activity of coffees brewed using different procedures (Italian, espresso and filter). Food Chemistry, 90(1-2), 133-139.

http://dx.doi.org/10.1016/j.foodchem.2004.03.037

Sandoval, A. J., \& Müller, A. J. (2017). Implications of non-equilibrium state glass transitions on carbohydrate polymers. In B. Bhandari \& Y. H. Roos (Eds.), Non-equilibrium states and glass transitions in foods (pp. 175-207). Cambridge: Woodhead Pubishing. http://dx.doi.org/10.1016/B978-0-08-100309-1.00011-0.

Sarabandi, K., Sadeghi Mahoonak, A., Hamishekar, H., Ghorbani, M., \& Jafari, S. M. (2018). Microencapsulation of casein hydrolysates: Physicochemical, antioxidant and microstructure properties. Journal of Food Engineering, 237, 86-95. http://dx.doi.org/10.1016/j.jfoodeng.2018.05.036

Sgarbieri, V. C. (1996). Proteínas em alimentos proteicos: Propriedades - degradações -modificações. São Paulo: Varela.

Silva, E. K., Toledo Hijo, A. A. C., Costa, J. M. G., Marques, G. R., Pereira, J., \& Borges, S. V. (2017). Influence of the addition of microencapsulated Swiss cheese bioaroma on the technical and sensory qualities of cheese bread. International Journal of Dairy Technology, 70(3), 372-379. http://dx.doi.org/10.1111/1471-0307.12358

Souza, A. L. R., Hidalgo-Chávez, D. W., Pontes, S. M., Gomes, F. S., Cabral, L. M. C., \& Tonon, R. V. (2018). Microencapsulation by spray drying of a lycopene-rich tomato concentrate : characterization and stability. LebensmittelWissenschaft + Technologie, 91, 286-292. http://dx.doi.org/10.1016/j.lwt.2018.01.053

Statista. The Portal for Statistic. (2018). Sales volume of soymilk worldwide in 2015 and 2018. Recuperado em 9 de maio de 2013, de https://www.statista.com/statistics/645662/soy-milk-sales-volume-worldwide 
Subtil, S. F., Rocha-Selmi, G., Thomazini, M., Trindade, M., Netto, F. M., \& Favaro-Trindade, C. S. (2014). Effect of spray drying on the sensory and physical properties of hydrolysed casein using gum arabic as the carrier. Journal of Food Science and Technology, 51(9), 2014-2021. PMid:25190858. http://dx.doi.org/10.1007/s13197-012-0722-z

Telis, V. R. N., \& Tonon, R. V. (2017). The effects of non-equilibrium states and storage conditions on glass transitions in food. In B. Bhandari \& Y. H. Roos (Eds.), Non-equilibrium states and glass transitions in foods (pp. 379-403). Cambridge: Woodhead Pubishing. http://dx.doi.org/10.1016/B978-0-08-100309-1.00020-1.

Wang, H. J., \& Murphy, P. A. (1996). Mass balance study of isoflavones during soybean processing. Journal of Agricultural and Food Chemistry, 44(8), 2377-2383. http://dx.doi.org/10.1021/jf950535p

Financiamento: Coordenação de Aperfeiçoamento de Pessoal de Nível Superior (CAPES) - Código Financeiro 001; Conselho Nacional de Desenvolvimento Científico e Tecnológico do CNPq (473117/2013-4); Fundação Araucária (160/2014). 